\title{
Harlequin Ichthyosis (IH), Autosomal Recessive Manifestation, A Review Article
}

\author{
Nanda Rachmad Putra Gofur ${ }^{1 *}$, Aisyah Rachmadani Putri Gofur ${ }^{2}$, Soesilaningtyas ${ }^{3}$, Rizki Nur \\ Rachman Putra Gofur ${ }^{4}$, Mega Kahdina ${ }^{4}$ and Hernalia Martadila Putri ${ }^{4}$ \\ ${ }^{1}$ Department of Health, Faculty of Vocational Studies, Universitas Airlangga, Indonesia
}

${ }^{2}$ Faculty of Dental Medicine, Universitas Airlangga, Indonesia

${ }^{3}$ Department of Dental Nursing, Poltekkes Kemenkes, Indonesia

${ }^{4}$ Faculty Of Medicine, Universitas Airlangga, Indonesia

*Corresponding author: Nanda Rachmad Putra Gofur, Department of Health, Faculty of Vocational Studies, Universitas Airlangga,

Surabaya, Indonesia

\section{ARTICLE INFO}

Received: 业 March 02, 2021

Published: 蔧 March 08, 2021

Citation: Nanda Rachmad PG, Aisyah Rachmadani PG, Soesilaningtyas, Rizki Nur Rachman PG, Mega K,et al., Harlequin Ichthyosis (IH), Autosomal Recessive Manifestation, A Review Article. Biomed J Sci \& Tech Res 34(3)-2021. BJSTR. MS.ID.005547.

Keywords: Harlequin Ichthyosis; Manifestation; Genetic

\section{ABSTRACT}

Introduction: Iktiosis is a group of skin diseases characterized by scaly skin all over the body. This can be hereditary or acquired. The term ichthyosis or ichthyosis comes from the Greek word ichthys which means "fish", because this condition resembles the scales of a fish. Iktiosis is a keratinization disorder in which the skin becomes thick, very dry and scaly. This condition was first reported in Indian and Chinese literature since several hundred years BC and was specifically discussed by Willan in 1808. In most cases, this disease is a hereditary disease, but sometimes ichthyosis is an acquired phenomenon, for example associated with lymphoma. Iktiosis has various types, but the common ones are Harlequin Ichthyosis (HI). In general, the clinical diagnosis can distinguish the various types of ichthyosis, however, a histopathological diagnostic examination is needed to confirm the diagnosis. Aims of this article is to review HI manifestation and diagnosis.

Discussion: Harlequin Ichthyosis (HI) is an autosomal recessive disorder that rarely occurs in newborns and often causes death within days of birth due to infection or dehydration due to complications. This ichthyosis is the most severe form of autosomal recessive congenital ichthyosis. The underlying genetic disorder in harlequin is a mutation of the lipid transport gene ABCA12 on the chromosome. The histopathologic features show dense hyperkeratosis, thickening of the stratum granulosum, hypogranulation and moderate acanthosis. There is a dense parakeratosis that extends to the hair follicles. The superficial cells of the stratum spinosum show changes in the cytoplasmic vacuole. The cells in the lower stratum spinosum and stratum basale are relatively normal. Normal adnexal structures are also seen. The underlying dermis layer did not show any abnormalities, nor did there appear to be inflammation in the dermis.

Conclusion: Harlequin ichthyosis (HI) is an autosomal recessive disorder that resulting in congenital ichthyosis. The underlying genetic disorder in harlequin is a mutation of the lipid transport gene ABCA12 on the chromosome. Acitretin is the most commonly used retinoid for neonates with HI.

\section{Introduction}

Iktiosis, discussed specifically in 1808 by William, is a keratinization disorder in which the skin becomes so dry and scaly that the skin becomes hard and looks like fish scales. In short, the keratinization process is defective so that the cells in the stratum corneum change shape and number of cells so that they change function. The process of epidermal differentiation is abnormal due to mutations of certain genes in various types of ichthyosis. To date, the number of genes identified and shown to cause ichthyosis in human patients has reached eleven. These genes cause changes 
in barrier function in the stratum corneum. The most common ichthyosis is ichthyosis vulgaris and has a fairly good prognosis. The rare and highest severity ichthyosis is harlequin ichthyosis and has a poor prognosis because of its high morbidity rate [1,2]. Iktiosis is a group of skin diseases characterized by scaly skin all over the body. This can be hereditary or acquired. The term ichthyosis or ichthyosis comes from the Greek word ichthys which means "fish", because this condition resembles the scales of a fish. Iktiosis is a keratinization disorder in which the skin becomes thick, very dry and scaly. This condition was first reported in Indian and Chinese literature since several hundred years BC and was specifically discussed by Willan in 1808. In most cases, this disease is a hereditary disease, but sometimes ichthyosis is an acquired phenomenon, for example associated with lymphoma [2].

The prevalence of hereditary ichthyosis is far more prevalent than acquired ichthyosis. In America, ichthyosis vulgaris (hereditary) has a prevalence of about 1 case in 300 people while acquired ichthyosis is very rare. One study in Berkshire, England, showed a frequency of 1 case in 250 school children. Congenital ichthyosis can occur at birth or some time afterward. The most common occurrences in most patients occur during the first year of life and predominantly occur at 5 years of age. The amount usually increases until puberty and then decreases with age. Acquired ichthyosis usually first appears in adulthood, but agerelated systemic diseases do occur in children. Usually affects the age of 3-12 months [1,3]. Iktiosis has various types, but the common ones are Harlequin Ichthyosis (HI). In general, the clinical diagnosis can distinguish the various types of ichthyosis, however, a histopathological diagnostic examination is needed to confirm the diagnosis. Aims of this article is to review HI manifestation and diagnosis.

\section{Discussion}

Harlequin Ichthyosis (HI) is an autosomal recessive disorder that rarely occurs in newborns and often causes death within days of birth due to infection or dehydration due to complications. This ichthyosis is the most severe form of autosomal recessive congenital ichthyosis. The underlying genetic disorder in harlequin is a mutation of the lipid transport gene ABCA12 on the chromosome. Mutations can be either homozygous or heterozygous. Immunohistococcal examination of the skin showed characteristic abnormalities in the structure of the lamellar granules and in the expression of epidermal keratin. The incidence of $\mathrm{HI}$ is about one per 300,000 births and no gender predilection is found [4,5]. The histopathologic features (Figure 1) show dense hyperkeratosis, thickening of the stratum granulosum, hypogranulation and moderate acanthosis. There is a dense parakeratosis that extends to the hair follicles. The superficial cells of the stratum spinosum show changes in the cytoplasmic vacuole. The cells in the lower stratum spinosum and stratum basale are relatively normal. Normal adnexal structures are also seen.

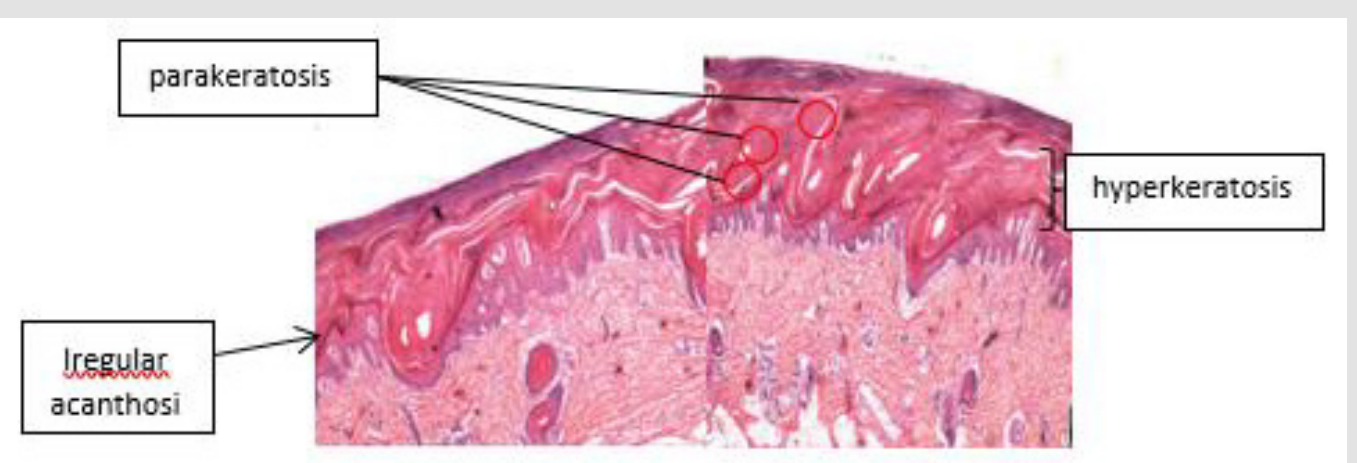

Figure 1: Harlequin ichiosis. On histological examination, there is a clear picture of hyperkeratosis (thickening of the stratum corneum), accompanied by parakeratosis (retention of the nucleus in the stratum corneum) with hypogranulosis and irregular acanthosis (epidermal thickening) 7.

The underlying dermis layer did not show any abnormalities, nor did there appear to be inflammation in the dermis [6]. On electron microscopy examination, large amounts of intracellular and extracellular lipids were found in the thickened stratum corneum. The stratum granulosum appears to be thinning. No solid core granules or keratohyaline granules were seen in the stratum granulosum or spinosum. There are several intracitoplasmic vacuoles in the stratum granulosum and corneum which cannot be further defined. Mitochondria are normal in size. The stratum granulosum and upper spinosum stratum showed a measurable reduction of desmosome tenofilament when compared to normal controls. Lower stratum spinosum, stratum basale and dermis are normal [6] (Figure 2). The clinical picture of the disease is characterized by a severe thickening of the stratum corneum, so that the baby is as if wrapped in a tight and shiny membrane, is in a semiflexed position, separated by a deep and reddish fissure. Ears may be absent or underdeveloped. This tight membrane can inhibit normal respiration, and newborns can have difficulty moving their arms and legs. The arms, legs, and fingers have flexion contractions and may be hypoplastic. Other clinical features include ectropion of the eye, eclabium of the mouth, hypoplasia of the nose and polydactyly. 


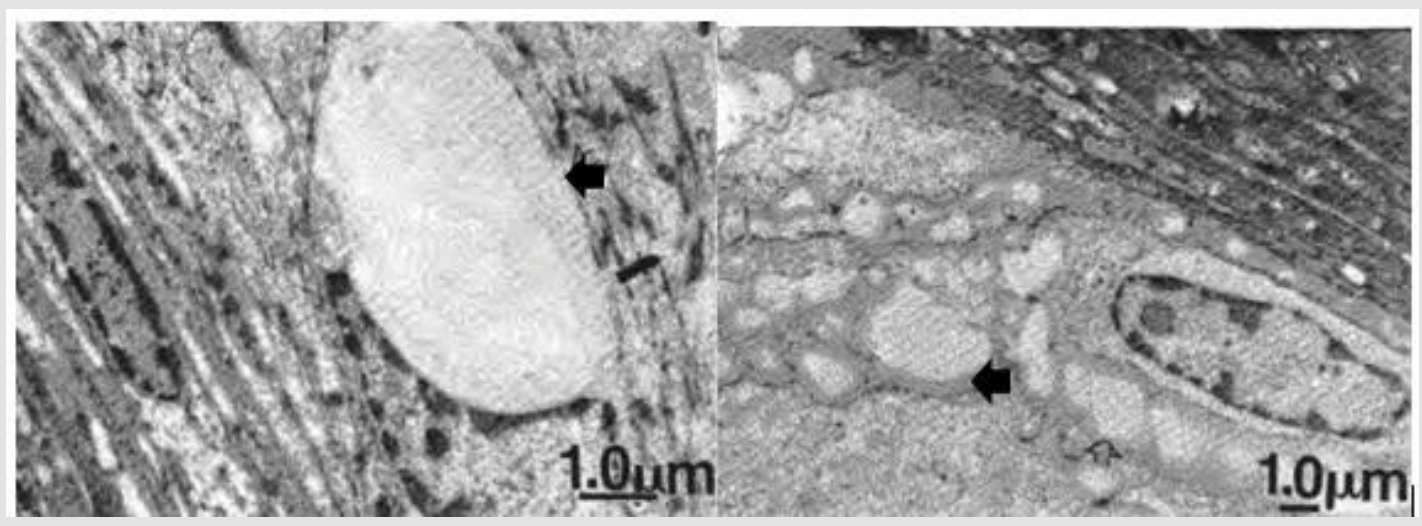

Figure 2: Electron micrograph of a patient with Harlequin ichthyosis. There is an appearance of extracellular lipids on the photo shown by arrows 6 .
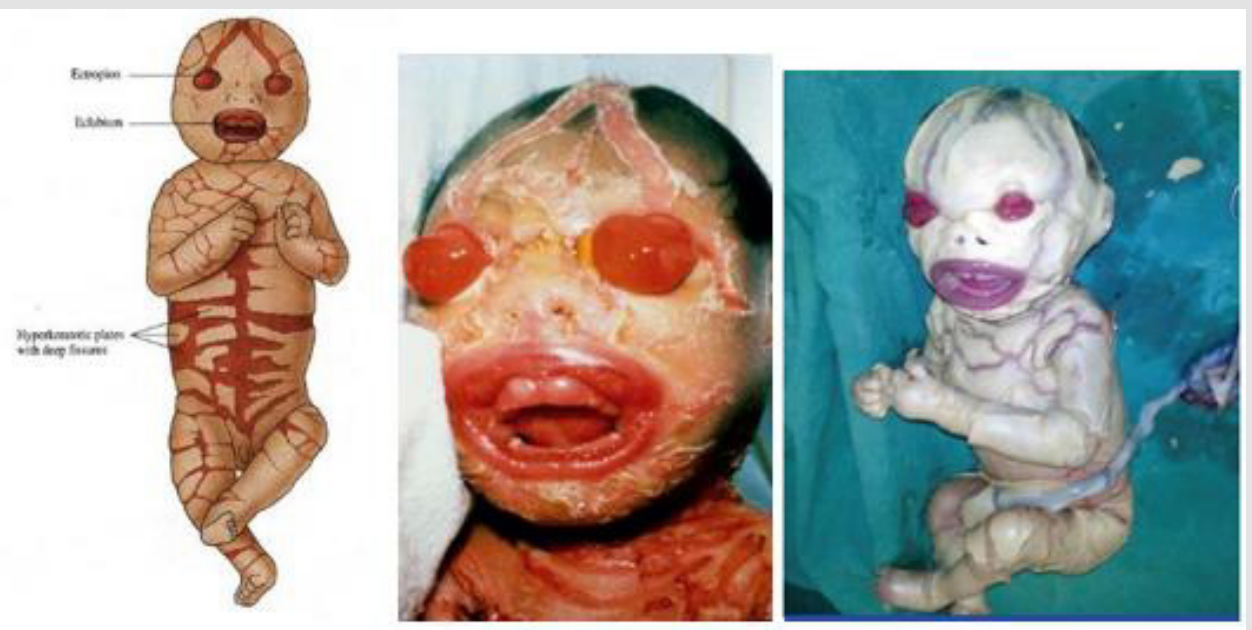

Figure 3: Clinical picture of a patient with harlequin ichthyosis. There was ectropion, eclabium, and deep reddish fissures all over the body 3 .

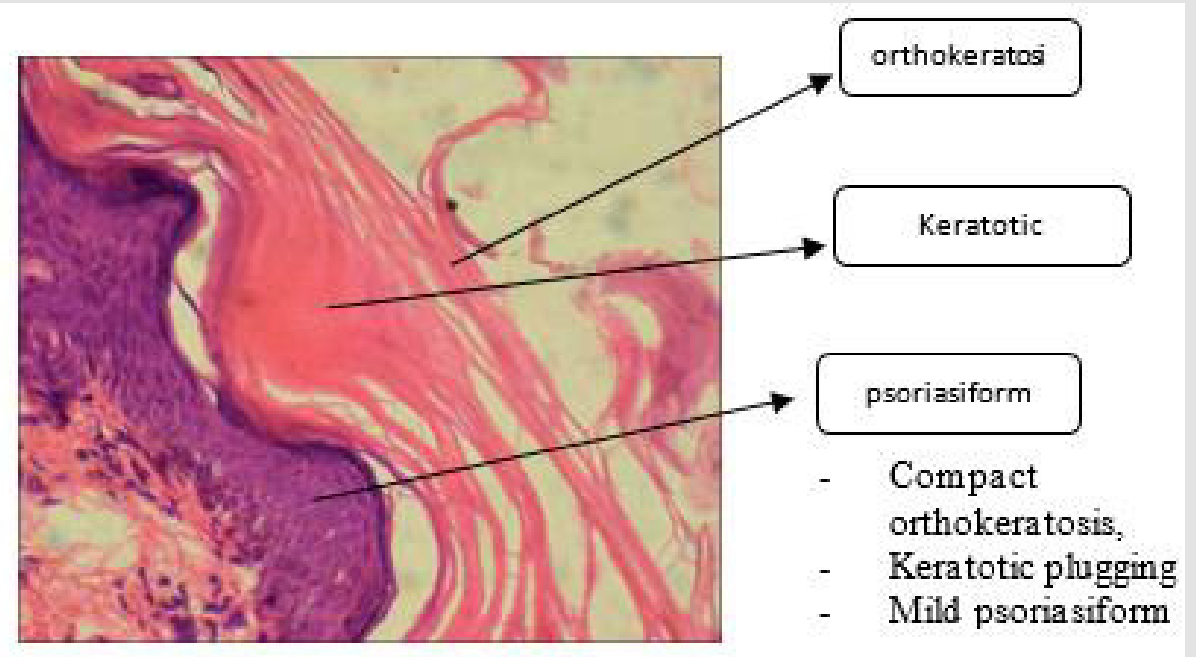

Figure 4: Histopathological picture of Collodion baby, one of the differential diagnoses of Harlequin ichthyosis 6. 
Skin damage is severely compromised, causing excessive water loss, electrolyte abnormalities, temperature dysregulation, and an increased risk of life-threatening infections. Poor feeding and impaired intestinal absorption are common [7,8] (Figure 3). Collodion baby is one of the differential diagnoses of harlequin ichthyosis, but it is not difficult to distinguish the two because the clinical picture is milder. Most collodion babies survive to adulthood. In these patients, the differential diagnosis of collodion babies can be ruled out because of the very severe contact with clinical manifestations. Other differential diagnoses include restrictive dermopathy, Conradi's disease, trichothyodystrophy Gaucher syndrome, Neu-Laxova syndrome, Dorfman-Chanarin syndrome [9] (Figure 4). Currently, the management of hereditary ichthyosis is symptomatic and focuses on hydration, lubrication and keratolysis [3]. Iktiotic skin, although thicker than normal skin, has decreased barrier function and increased transepidermal fluid loss, so that hydration efforts, such as use of moisturizers and long showers, can smoothen skin surface. Areas of hyperkeratosis that are well hydrated can be easier to treat using a mild abrasive agent (sponge, bath wool, stones, etc.). The use of oils while bathing or lubricants such as body lotions, creams, oils, ointments, or vaseline can prolong hydration and smoothness [10].

Management of HI patients is supportive, consisting of fluid and electrolyte management, topical drugs for skin hydration in the form of emollients containing keratolytic ingredients including urea, salicylic acid, propylene glycol, lactic acid and their combinations. Topical retinoids, vitamin D, petrolatum or lanolin, moisturizing soap is also quite effective. Broad spectrum antibiotics as prophylaxis are often given, but their effectiveness is still doubtful. - Eye consultation is important to prevent blindness. Giving keratolytic material is intended to accelerate the desquamation process of corneocytes so that it can remove squama and thin the thick stratum corneum. Systemic retinoid therapy with isotretinoin or acitretin can induce marked clinical improvement in some cases of ichthyosis. Acitretin is the most commonly used retinoid for neonates with $\mathrm{HI}[10]$.

\section{ISSN: 2574-1241}

DOI: $10.26717 /$ BJSTR.2021.34.005547

Nanda Rachmad Putra Gofur. Biomed J Sci \& Tech Res

cC) This work is licensed under Creative Commons Attribution 4.0 License

Submission Link: https://biomedres.us/submit-manuscript.php

\section{Conclusion}

Harlequin ichthyosis (HI) is an autosomal recessive disorder that resulting in congenital ichthyosis. The underlying genetic disorder in harlequin is a mutation of the lipid transport gene ABCA12 on the chromosome. Acitretin is the most commonly used retinoid for neonates with $\mathrm{HI}$.

\section{References}

1. Arnold Harry L, Richard B Odom, William D James (2015) Andrew's Diseases of The Skin Clinical Dermatology. In Arnold Harry L, Richard B Odom, William D James (Eds.), (12 ${ }^{\text {th }}$ edn.), WB Saunders Company, Philadelphia pp. 88-122.

2. Akiyama M (2011) The roles of ABCA12 in keratinocyte differentiation and lipid barrier formation in the epidermis. Dermatoendocrinol 3(2): 107-112.

3. Fleckman P, DiGiovanna JJ (2012) The Ichthyoses, Fitzpatrick's Dermatology in General Medicine. In Fleckman P, DiGiovanna JJ (Eds.), McGraw-Hill, New York 8: 507-538.

4. Kelsell DP, Norget EE, Unsworth H, Teh MT, Cullup T (2005) Mutations in ABCA12 underlie the severe congenital skin disease harlequin ichtyosis. Am J Hum Genet 76(5): 794-803.

5. Kubo Y Urano, Y Matsuda R (2011) Ichthyosis hystrix, Curth-Macklin type: a new sporadic case with a novel mutation of keratin. Arch Dermatol 147(8): 999-1001.

6. Dahlstrom J, McDonald T, Maxwell L, Jain S (1995) Harlequin ichthyosis A case report. Pathology, 27(3): 289-292

7. Morita R, Takeichi T, Okuno Y (2017) A case of lamellar ichthyosis with a novel TGM1 mutation and parkinson's disease. European Journal of Dermatology 27(4): 1-9.

8. Reginatto F, T Cestari (2014) Hereditary Disease in The Newborn: Ichthyosis and Ectodermal Dysplasias. Advances in Pediatric Dermatology-2. In Reginatto F, T Cestari (Eds.), (1 ${ }^{\text {st }}$ Edn.), JP Medical Ltd, New Delhi pp. 34-50.

9. Nomura T, Akiyama M, Sandilands A (2008) Specific filaggrin mutations cause ichthyosis vulgaris and are significantly associated with atopic dermatitis in japan. Journal of Investigative Dermatology 128(6): 14361441

10. Akiyama M (2011) Updated molecular genetics and pathogenesis of ichthyoses. Nagoya University Journal. Nagoya J Med Sci 73(3-4): 79-90.

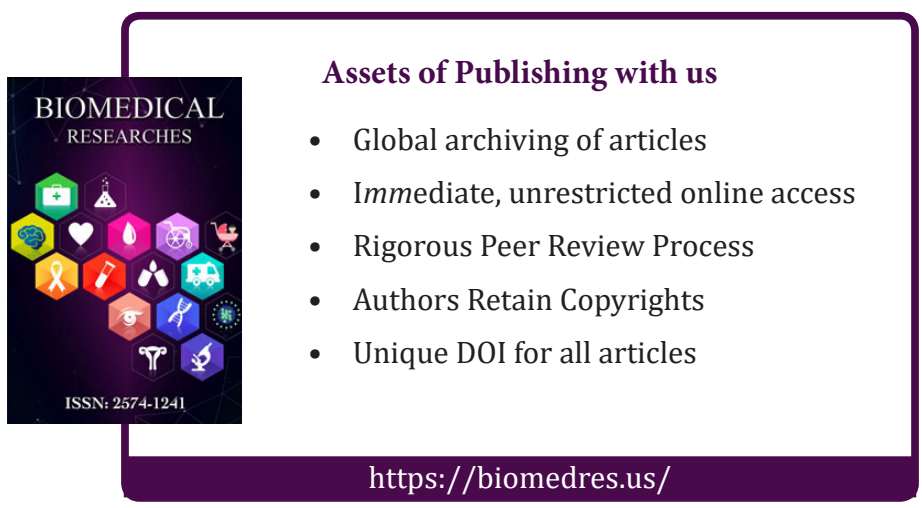

